\title{
Breast Conservative Therapy
}

\author{
Ajaz Ahmad Malik, M.S., Khursheed Alam Wani, M.S., Sheikh Riyaz Ahmad, M.S. \\ Department of General Surgery, Sher-i-Kashmir Institute of Medical Sciences, Srinagar
}

\section{A B S T R A C T}

Breast cancer is the most frequently diagnosed life-threatening cancer in women worldwide. It is the leading cause of cancer-related death among women. In the West, it is often first detected as an abnormality on a mammogram, before it is felt by the patient or the healthcare provider. However, in the Indian subcontinent, presentation is often late. Surgery is considered primary treatment for breast cancer. Many patients with early-stage breast cancer are cured with surgery alone. In this review, various surgical aspects of breast-cancer are discussed with focus on breast conservative surgery. JMS 2012;15(1):7-14.

Every three minutes, a woman in the United States is diagnosed with breast cancer. Every twelve minutes a woman dies from breast cancer. Breast cancer comprises $22.9 \%$ of all cancers (excluding non-melanoma skin cancers) in women, worldwide. ${ }^{1}$ In 2008, breast cancer caused 458,503 deaths worldwide (13.7\% of cancer deaths in women). ${ }^{1}$ Breast cancer is more than 100 times more common in women than breast cancer in men, although males tend to have poorer outcomes due to delays in diagnosis. ${ }^{2,3}$ No one dies of cancer in the breast, only of cancer that has spread to other parts of the body. Breast cancer is the commonest cause of cancer death in women worldwide. Rates vary about five-fold around the world, but they are increasing in regions that until recently had low rates of the disease. Lot of progress has been made in the understanding of risk factors (Table 1) and management of breast cancer. The concept of radical surgery has been replaced by the more conservative one without significant compromise in terms of results.

Opting for simple mastectomy or wide local excision and adjuvant radiotherapy, rather than obligatory mastectomy, be it radical or modified radical, reflects a significant shift in the understanding of breast cancer pathology and management. ${ }^{4}$

\section{Correspondence:}

Dr. Ajaz Ahmad Malik

Additional Professor

Department of General Surgery,

SKIMS, Soura Srinagar (J\&K), India - 190011

E-Mail: ajazamalik@yahoo.com
Multimodal treatments - both loco-regional, in the form of breast conservation surgery and radiotherapy, and systemic like endocrine treatment and chemotherapy, has resulted in reduced postsurgical morbidity without compromising oncological outcomes. ${ }^{5}$ Neo-adjuvant chemotherapy or endocrine therapy is increasingly being applied to improve the chance of successful conservation surgery in the same way as it can render operable the inoperable. ${ }^{6,7}$ Before discussing Breast conservative therapy, a brief mention regarding Breast cancer as such, is made below.

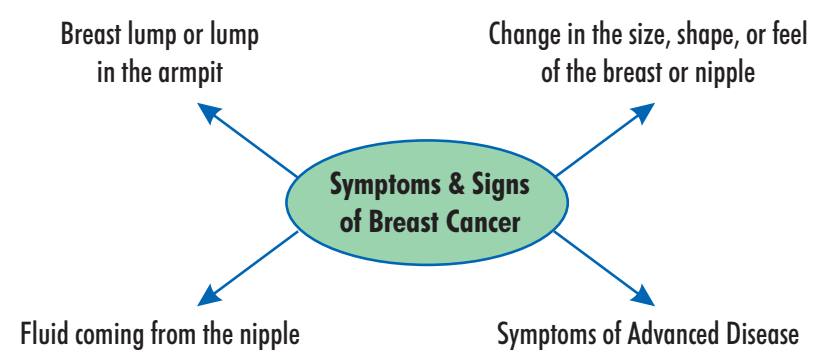

FIGURE 1: Symptoms and signs of breast cancer

\section{Symptoms}

Early breast cancer usually does not cause symptoms and depend upon the stage of disease(Figure 1). This is why regular breast exams are important. As the cancer grows, symptoms may include: 


\begin{tabular}{|c|c|c|c|c|c|c|c|c|c|}
\hline 1. Age & & & $\begin{array}{l}\text { Sex } \\
\text { BRCA } \\
\text { BRCA }\end{array}$ & $\begin{array}{l}41 \text { and } \\
42\end{array}$ & 3. Heredity & 4. Prior cancers & 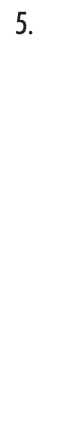 & $\begin{array}{ll}\text { Dietary factors } \\
5.1 & \text { Alcohol } \\
5.2 & \text { Fat intake } \\
5.3 & \text { Specific dietary } \\
& \text { fatty acids } \\
5.4 & \text { Phytoestrogens } \\
5.5 & \text { Vitamin D } \\
5.6 & \text { Brassica vegetables } \\
5.7 & \text { Country diet } \\
5.8 & \text { Mushrooms } \\
5.9 & \text { lodine deficiency }\end{array}$ & $\begin{array}{l}\text { Obesity and } \\
\text { Lack of Exercise }\end{array}$ \\
\hline $\begin{array}{c}\text { 7. Horn } \\
7.1 \\
\\
7.2 \\
7.3 \\
7.4 \\
7.5\end{array}$ & $\begin{array}{l}\text { mones } \\
\text { Pregnancy, childbearing } \\
\text { and breast feeding } \\
\text { Hormonal contraception } \\
\text { Hormone replacement } \\
\text { therapy } \\
\text { Oophorectomy and } \\
\text { mastectomy } \\
\text { Hormonal therapy } \\
7.5 .1 \text { Selective estrogen } \\
\text { receptor modulators } \\
\text { (SERMs) } \\
\text { Endocrine disruptors }\end{array}$ & 8. & $\begin{array}{l}\text { Enviro } \\
8.1 \\
8.2 \\
8.3 \\
8.4 \\
8.5 \\
8.6 \\
\\
8.7 \\
8.8 \\
\\
8.9 \\
8.10 \\
8.11\end{array}$ & $\begin{array}{l}\text { ronmental factors } \\
\text { Xeno-estrogens } \\
8.1 .1 \text { Bisphenol A } \\
\text { Aromatic Amines } \\
\text { Benzene } \\
\text { DDT } \\
\text { Ethylene oxide } \\
\text { Polycyclic aromatic } \\
\text { hydrocarbons } \\
\text { Vinyl chloride } \\
\text { Tobacco } \\
\text { 8.8.1 Passive smoking } \\
\text { Radiation } \\
\text { Dioxins } \\
\text { Light at night and } \\
\text { disturbance of } \\
\text { circadian rhythm }\end{array}$ & $\begin{array}{l}\text { 9. Racial and } \\
\text { socioeconomic } \\
\text { factors }\end{array}$ & $\begin{array}{l}\text { 10. Factors with inconclusive } \\
\text { research } \\
10.1 \text { Tea } \\
10.2 \text { 1,3-Butadiene } \\
10.3 \text { Mammographic density } \\
10.4 \text { Red No. } 3\end{array}$ & 11. & $\begin{array}{l}\text { Factors with minimal } \\
\text { or no impact } \\
11.1 \text { Abortion } \\
11.2 \text { Bras } \\
11.3 \text { Deodorants } \\
11.4 \text { Fertility treatments } \\
11.5 \text { Folic acid (folate) } \\
11.6 \text { Viruses }\end{array}$ & \\
\hline
\end{tabular}

- Breast lump or lump in the armpit that is hard, has uneven edges, and usually does not hurt.

- Change in the size, shape, or feel of the breast or nipple for example, you may have redness, dimpling, or puckering that looks like the skin of an orange(Figure 2).

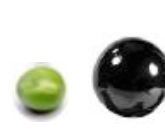

$1 \mathrm{~cm} \quad 2 \mathrm{~cm}$

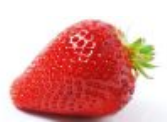

$3-4 \mathrm{~cm}$

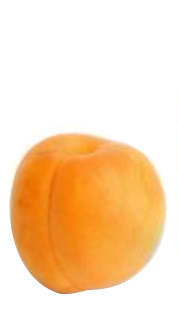

$5 \mathrm{~cm}$

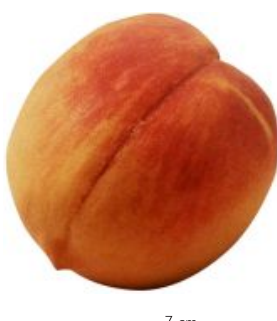

$7 \mathrm{~cm}$
FIGURE 2: Showing tumor size in terms of pea, marble ball, strawberry, apricot and peach

- Fluid coming from the nipple - may be bloody, clear to yellow, green, and look like pus.

- Men can get breast cancer, too. Symptoms include breast lump and breast pain and tenderness.

- Symptoms of advanced breast cancer may include:

- Bone pain

- Breast pain or discomfort

- $\quad$ Skin ulcers

- Swelling of one arm (next to the breast with cancer)

- Weight loss

\section{Breast cancer staging}

After breast cancer has been diagnosed, tests are done to find out if cancer cells have spread within the breast or to other parts of the body. The process used to find out whether the cancer has spread within the breast or to other parts of the body is called staging. The information gathered from the staging process determines the stage of the disease. It is important to know the stage, in order to plan treatment.(Box 1). The

Box 1. Stagewise treatment of breast cancer

Stage of tumor Rxoption

Stage 0 Lcis - regular follow up with or without tamoxifen. Dcis - if $<0.5 \mathrm{~cm}$ papillary, cribriform or solid type lumpectomy with or without radiotherapy. If widespread-mastectomy.

Stage I,lla,llb Mastectomy with lymph node assessment or lumpectomy with or without radiotherapy with lymph node assessment $+/$ chemotherapy $+/$-hormonal therapy.

Stage Illa Modified radical mastectomy followed by chemotherapy followed by radiotherapy $+/$-hormonal therapy.

Stage lllb Neo-adjuvant chemotherapy followed by modified radical mastectomy followed by chemotherapy followed by radiotherapy + -hormonal therapy.

Stage IV Palliative treatment. Hormonal therapy for hormone receptor positive tumor, with metastasis to bone or soft tissue only or asymptomatic visceral metastasis. chemotherapy for symptomatic visceral metastasis. 
following tests and procedures may be used in the staging process:

- Chest x-ray: An x-ray of the organs and bones inside the chest.

- $\quad$ CT scan (CAT scan).

- $\quad$ Bone scan: A procedure to check if there are rapidly dividing cells, such as cancer cells, in the bone. A very small amount of radioactive material is injected into a vein and travels through the bloodstream. The radioactive material collects in the bones and is detected by a scanner.

- $\quad$ PET scan (positron emission tomography scan): A procedure to find malignant tumor cells in the body. A small amount of radioactive glucose (sugar) is injected into a vein. The PET scanner rotates around the body and makes a picture of where glucose is being used in the body. Malignant tumor cells show up brighter in the picture because they are more active and take up more glucose than normal cells do.

There are three ways that cancer spreads in the body.

- Through tissue. Cancer invades the surrounding normal tissue.

- $\quad$ Through the lymph system. Cancer invades the lymph system and travels through the lymph vessels to other places in the body.

- Through the blood. Cancer invades the veins and capillaries and travels through the blood to other places in the body.

When cancer cells break away from the primary (original) tumor and travel through the lymph or blood to other places in the body, another (secondary) tumor may form. This process is called metastasis. The secondary (metastatic) tumor is the same type of cancer as the primary tumor. For example, if breast cancer spreads to the bones, the cancer cells in the bones are actually breast cancer cells. The disease is metastatic breast cancer, not bone cancer.

The following stages are used for breast cancer:

\section{Stage 0 (carcinoma in situ)}

There are 2 types of breast carcinoma in situ:

- Ductal carcinoma in situ (DCIS)

- Lobular carcinoma in situ (LCIS)

\section{Stage I} IA and IB

In stage I, cancer has formed. Stage I is divided into stages

- In stage IA, the tumor is 2 centimeters or smaller and has not spread outside the breast.

- In stage IB, either:

o No tumor is found in the breast, but small clusters of cancer cells (larger than 0.2 millimeter but not larger than 2 millimeters) are found in the lymph nodes; or

\section{Stage II}

Stage II is divided into stages IIA and IIB.

- In stage IIA:

o No tumor is found in the breast, but cancer is found in the axillary lymph nodes (lymph nodes under the arm); or

o The tumor is 2 centimeters or smaller and has spread to the axillary lymph nodes; or

o The tumor is larger than 2 centimeters but not larger than 5 centimeters and has not spread to the axillary lymph nodes.

- In stage IIB, the tumor is either:

o Larger than 2 centimeters but not larger than 5 centimeters and has spread to the axillary lymph nodes; or

o Larger than 5 centimeters but has not spread to the axillary lymph nodes.

\section{Stage IIIA}

In stage IIIA:

- No tumor is found in the breast. Cancer is found in axillary lymph nodes that are attached to each other or to other structures, or cancer may be found in lymph nodes near the breastbone; or

- The tumor is 2 centimeters or smaller. Cancer has spread to axillary lymph nodes that are attached to each other or to other structures, or cancer may have spread to lymph nodes near the breastbone; or

- The tumor is larger than 2 centimeters but not larger than 5 centimeters. Cancer has spread to axillary lymph nodes that are attached to each other or to other structures, or cancer may have spread to lymph nodes near the breastbone; or

- The tumor is larger than 5 centimeters. Cancer has spread to axillary lymph nodes that may be attached to each other or to other structures, or cancer may have spread to lymph nodes near the breastbone.

\section{Stage IIIB}

In stage IIIB, the tumor may be any size and cancer:

- Has spread to the chest wall and/or the skin of the breast; and

- May have spread to axillary lymph nodes that may be attached to each other or to other structures, or cancer may have spread to lymph nodes near the breastbone.

Cancer that has spread to the skin of the breast is inflammatory breast cancer. See the section on Inflammatory Breast Cancer for more information. 


\section{Stage IIIC}

In stage IIIC, there may be no sign of cancer in the breast or the tumor may be any size and may have spread to the chest wall and/or the skin of the breast. Also, cancer:

- Has spread to lymph nodes above or below the collarbone; and

- May have spread to axillary lymph nodes or to lymph nodes near the breastbone.

Cancer that has spread to the skin of the breast is inflammatory breast cancer. See the section on Inflammatory Breast Cancer for more information.

Stage IIIC breast cancer is divided into operable and inoperable stage IIIC

In operable stage IIIC, the cancer:

- Is found in ten or more axillary lymph nodes; or

- Is found in lymph nodes below the collarbone; or

- Is found in axillary lymph nodes and in lymph nodes near the breastbone.

In inoperable stage IIIC breast cancer, the cancer has spread to the lymph nodes above the collar bone.

\section{Stage IV}

In stage IV, the cancer has spread to other organs of the body, most often the bones, lungs, liver, or brain.

\section{Breast conservative Therapy (BCT)}

Breast conservation therapy(Amalgam of breast conserving surgery and radiation therapy to the breast), has revolutionized the treatment of breast cancer over the last few decades. Increased demand by patients for breast preservation and heightened interest by breast surgeons in the performance of cosmetically superior partial and segmental resections for breast cancers, has resulted in tremendous advance in BCT. Improvement in approaches of delivery of breast irradiation from whole breast to accelerated partial breast has allowed more patients to opt for breast conservation and allowed for what appears to be comparable measurable outcomes in emerging data. In addition state-of-the-art chemotherapeutic and hormonal therapies have allowed improved outcomes of patients from both loco regional recurrence and overall survival standpoints The aim of breast conserving surgery (BCS) is to excise all invasive and in situ cancer and to achieve long-term disease control whilst at the same time minimising local morbidity and ensuring a good cosmetic result. BCS is as effective as mastectomy in terms of disease outcome and overall survival ${ }^{8}$ but confers the advantages of better cosmesis, less psychological morbidity, improved body image, sexuality and self-esteem. ${ }^{9}$

\section{Why Breast Conservative Surgery?}

1. Ca breast is a local manifestation of a systemic disease. Local radicality does not change survival.

2. Cosmetic considerations.
3. Preservation of the nipple, an important sensate focus.

\section{Where to do breast conservative surgery?}

Presently Breast conservative surgery is being performed in most cases of Stage I and II Breast cancers. The oncoplastic surgical techniques allows larger tumors to be excised safely without compromising cosmetic outcomes. Currently, the only absolute contraindications to breast conservation relate to

1. Tumors with chestwall involvement,

2. Significant skin involvement, and

3. Patients with either extensive malignant microcalcifications or inflammatory carcinoma. ${ }^{10,11}$

And the relative contraindications are (meticulous preoperative planning is essential if conservation is to be successful. ${ }^{12}$

1. Multifocal and multicentric tumors (such patients need careful counselling regarding the possible need for further surgery if excision is incomplete, and the increased risk of locoregional recurrence).

2. Pregnancy(except near term).

3. Collagen vascular disease, previous irradiation etc.

\section{Principles of Breast Conservative Surgery}

I) General principles
a) Preference of incision
b) To prevent nipple deviation

II) Excision of $<10 \%$ of breast volume, methods

III) Excision of $10-20 \%$ breast volume methods:
a) Volume displacement
b) Central tumours
c) Peripheral tumours

IV) Techniques for excision of $>20 \%$ of breast volume:

a) Tissue transfer

A) Preference of incision

1. Incisions should follow Langer's lines, semicircular, concentric to the edge of the areola, or Kraissl's lines, parallel to the horizontal skin creases

2. Radial incisions can be useful, but care must be taken to ensure that the nipple-areola complex is not likely to be displaced as the scar contracts during the process of wound healing and radiotherapy.

3. A circumareolar incision can give good access to most lesions except those at the extreme periphery of the breast.

B) To prevent nipple deviation.

1. The skin overlying the cancer need not to be excised except if there are concerns regarding skin involvement, as, if there is in-drawing of the skin or fixed dimpling. 
2. Scarring, following wide local excision and radiotherapy changes tend to deviate nipple deviation towards the scar. To prevent this undermining of the skin and disconnecting the ducts behind the nipple-areola complex can be done and in addition the remaining glandular tissue can also be undermined to allow rotation and approximation of tissue into the defect.

3. De-epithelialisation of a crescent of skin from the areolar edge that is opposite to the scar and resiting the nipple to adjust for anticipated deviation often is helpful.

ii) Excision of $<10 \%$ of breast volume, methods.

A. For such cancers, acceptable cosmetic results are achieved by excision of up to $10 \%$ of breast volume as a simple wide local excision and generously undermining the surrounding glandular tissue to allow it to fill the wide excision cavity.

B. For defects despite breast remodelling the use of autologous fat transfer. ${ }^{13}$

iii) Excision of 10-20\% breast volume methods (Table 2)

TABLE 2.

Mammoplasty techniques for resection of 10-20\% of breast volume:
Glandular remodeling
Inferior pedicle
Superior pedicle
Vertical scar
Round block
Grisotti flaps

Breast cancers occupying up to $20 \%$ of breast volume, volume displacement by mobilisation and transposition of neighbouring glandular tissue with or without overlying skin may be required to fill the defect. ${ }^{14}$

Patients with adequate breast volume may wish to undergo therapeutic mammoplasty. ${ }^{15}$ Surgery to the contralateral breast may be requested to improve symmetry and may take the form of a reduction mammoplasty or mastopexy

iv) Excision of $>20 \%$ of breast volume

For cancers occupying $20-40 \%$ of the breast, volume displacement alone may not be sufficient and thus volume replacement by autologous tissue transfer may become necessary.

\section{Special considerations}

\section{Central Tumours Occupying $10-20 \%$ of Breast Volume}

a. Central tumours (subareolar tumours) may be safely approached by central excision with resection of the nipple-areola complex, ${ }^{16,17}$ and the wound can be closed with a purse string or horizontal suture. (but this may reduce the projection of the breast mound).

b. Grisotti dermoglandular flap is more appropriate for larger breasts with greater degrees of ptosis. ${ }^{18} \mathrm{~A}$ dermoglandular flap is harvested from the inferolateral breast after excision of the nipple-areola complex and the underlying tumour followed by de-epithelialisation of flap apart from the circle of skin destined to reconstruct the nipple(Free rotation depends on the flap being freed from the prepectoral fascia).

c. Inverted-T (WISE pattern) mammoplasty ${ }^{15}$ - excising the nipple-areola complex, is a popular alternative, with the nipple potentially being reconstructed at a later date, is a popular alternative.

d. Benelli's round block technique - an alternate option for central tumours not involving the nipple-areola complex. Concentric circles are incised around the areola, and the skin resected (allowing access to the periareolar tissue), and the skin is closed by means of a purse string suture. ${ }^{19,20}$

e. Alternatively central tumours not involving the nippleareola complex such may be excised in combination with a batwing mastopexy (otherwise known as the omega plasty) while preserving the nipple-areola complex. ${ }^{21}$ Semicircular incisions are made: one circumareolar and the other a short distance away, and these are joined by angled "wings" to each side of the areola and after excision the defect is closed by advancing the breast tissue and closing the skin.

\section{Peripheral Tumours Occupying $10-20 \%$ of Breast Volume}

Different oncoplastic techniques lend themselves to excision of lesions in certain locations (Table 3). Tumours above the nipple-areola complex may be excised and the defect filled with an inferior pedicle mammoplasty.

\begin{tabular}{|c|c|}
\hline Tumour location & Oncoplastic technique \\
\hline Superior to NAC & $\begin{array}{l}\text { Periareolar (Benelli) mammoplasty } \\
\text { Inferior pedicle (Grisotti) mammoplasty }\end{array}$ \\
\hline Lateral to NAC & Lateral mammoplasty \\
\hline Medial to NAC & Medial mammoplasty \\
\hline Lower outer/inner quadrant & $\begin{array}{l}\text { L-mammoplasty } \\
\text { J-mammoplasty }\end{array}$ \\
\hline Inferior to NAC & $\begin{array}{l}\text { Vertical scar mammoplasty } \\
\text { Inverted T (WISE) mammoplasty }\end{array}$ \\
\hline Inframammary fold & IMF-plasty \\
\hline
\end{tabular}

1. Tumours above the nipple-areola complex may be excised and the defect filled with an inferior pedicle mammoplasty.

2. Excision of tumours in the lateral aspect of the breast: tumours inferior to the nipple-areola complex may be excised by means of a vertical mammoplasty ${ }^{22,23}$ or nipplesparing inverted-T mammoplasty. ${ }^{15}$ 
3. Moderately sized tumours in the lower outer quadrant may be resected using a modified approach, sometimes referred to as the J-mammoplasty, with larger tumours excised via an inverted-T or L-mammoplasty.

The inverted-T mammoplasty gives a satisfactory result and is in proportion to the patient's body habitus. Reduction mammoplasty of the contralateral breast, to improve symmetry, is planned to be performed six months after completion of adjuvant radiotherapy.

Tumours close to the inframammary fold may be removed by excising an ellipse of skin and breast tissue and simply closing the resulting defect. Although this reduces the distance from nipple to inframammary fold, this is often not apparent in patients with preexisting ptosis.

\section{Cosmesis after Extensive Excision of 20- $40 \%$ of Breast Volume: Techniques of Tissue Transfer}

When more than $20 \%$ of breast volume is excised, tissue mobilisation alone may not succeed in achieving a satisfactory result and, unless the patient desires a much smaller breast, volume replacement by tissue transfer may be

1. A pedicled latissimus dorsi miniflap, which can be mobilised to fill a defect in any quadrant. ${ }^{24,25}$ The first stage of the procedure involves excision of the breast lesion, and then the latissimus dorsi miniflap is used to fill the defect after a delay of one or two weeks to allow the margin status to be assessed. ${ }^{26}$ If intraoperative analysis of surgical margins by frozen section is available, then a single stage procedure is feasible. . $^{27,28}$

2. Alternatives include mobilisation of axillary tissue on a thoracodorsal artery perforator lipodermal flap ${ }^{29}$ or use of intercostal artery perforator flaps. ${ }^{28}$

3. One novel approach adopted is to laparoscopically harvest an omental flap to fill the local defect. ${ }^{30}$ Whereas pedicled flaps usually withstand radiotherapy, albeit with a substantial rate of complications, the use of free flaps in this context is contraindicated.

\section{Management of Multifocal and Multicentric Tumours}

Multifocal tumours, within the same quadrant, and multicentric tumours, in different quadrants or in the same quadrant but widely separated $(>5 \mathrm{~cm})$, is controversial. Although these scenarios would dictate mastectomy as the only oncologically sound procedure, but If a conservative procedure is to be considered in these patients, careful selection is required with regard to tumour location and breast size and shape and counselled regarding the increased likelihood of further surgery should margins be positive, and, and possible increased risk of local recurrence, which may entail completion mastectomy. A retrospective study comparing outcomes of patients with multifocal and unifocal cancers showed equivalent overall survival and no increase in risk of locoregional recurrence. $^{31}$

1. For tumours closely spaced within the breast may be removed together utilising an appropriate technique such as an omegaplasty or inverted-T mammoplasty.

2. Separate wide excisions are more appropriate for tumours separated by $>5 \mathrm{~cm}$. preoperative use of magnetic resonance imaging, and image-guided localisation of all lesions to be excised is essential and access to intraoperative frozen section histology, is desirable in terms of reducing the need for further surgery in case of margin involvement.

\section{Local Recurrence or Metachronous Ipsilateral Primary Breast Cancer}

Breast conservation procedure in patients who have previously undergone wide local excision for an ipsilateral cancer is controversial. Whole-breast radiotherapy can only be given once, and therefore further breast conservation surgery alone, versus mastectomy, is subject to the same disparity in efficacy as when wide local excision, without radiotherapy, is compared with mastectomy for primary breast cancer. ${ }^{32} 40 \%$ of women treated in this way will have local recurrence. Given these odds, many women will opt for mastectomy rather than any further attempt at breast conservation, but partial breast radiotherapy may be used in this context in an attempt to reduce the risk of failure. ${ }^{33}$ At present, partial breast radiotherapy is only offered to a minority of patients. As these techniques gain wider acceptance and enter routine practice, a greater proportion of patients may be eligible for further breast conservation surgery to manage local recurrence or metachronous ipsilateral primary breast cancer.

\section{Symmetry: When to Perform Contralateral Surgery}

Large volume excisions, often result in noticeable asymmetry, which should be corrected. No consensus regarding the optimal timing of contralateral surgery exists. Simultaneous procedures reduce patient inconvenience and the need for a second admission and general anaesthetic

Conversely, postradiotherapy changes can be unpredictable, and, therefore, some prefer to perform the contralateral reduction after these have had time to settle, to improve the chance of achieving good symmetry. A delayed approach also takes into account the possibility that further surgery may be required in the form of excision of margins or completion mastectomy if excision is incomplete. ${ }^{34}$ If contralateral reduction is planned as a simultaneous procedure, then slightly more tissue should be excised and the nipple placed marginally higher, to mimic the predicted postradiotherapy shape. 


\section{Our Experience with breast Conservation Surgery}

We at SKIMS are routinely doing breast conservative procedures in stage I and II breast cancers. The results with this procedure have been satisfactory. Recently a research project was carried in this regard by the joint collaboration of department of General Surgery with department of Plastic Surgery. The aims of this project were:

1) To analyze the applicability of skin sparing mastectomy (SSM) with immediate breast reconstruction (IBR),

2) Comparison of breast conserving surgery without reconstruction and SSM with IBR in terms of patient satisfaction, psychological impact and local recurrence rate, and

3) Follow up of patients in prospective group to look for cosmesis, breast mound, breast skin color and flap necrosis. It was observed that SSM is oncologically safe and SSM and IBR are appropriate treatment for patients with early breast cancer; the use of SSM has improved breast reconstruction outcomes and has thereby enhanced the quality of life of our patients.

\section{Future of Breast Conservation surgery}

Endoscopic breast surgery for benign and malignant disease has been described in a number of small case series. ${ }^{35,36}$ Subcutaneous mastectomy and wide local excision have been performed by creating a working space through Carbon dioxide insufflation. Although usually employed in the management of ductal carcinoma in situ, excision of T1 carcinomas has also been successfully performed. ${ }^{37}$ The ability to reliably excise tumours with clear surgical margins is not well established due to the small size of these case reports, and more work is needed before they will be readily adopted into routine practice. $^{38}$

Radiofrequency ablation for small breast tumours is currently under evaluation. ${ }^{39}$ The procedure can be monitored intraoperatively by ultrasound and postoperatively by magnetic resonance imaging. Wide local excision may be performed after radiofrequency ablation to ensure adequate oncological treatment. ${ }^{40}$ Concerns regarding the ability to accurately assess response by magnetic resonance imaging alone currently preclude the use of this technique in isolation. ${ }^{41}$ Fine-needle aspiration cytology in conjunction with magnetic resonance imaging has been used to assess response in patients not undergoing excision, ${ }^{42}$ but this approach should not be employed outside of clinical research given its unproven sensitivity and inability to adequately sample the "margin" of ablation and because of the paucity of data related to long-term outcomes.

\section{References}

1. World Cancer Report. International Agency for Research on Cancer. 2008. http://globocan.iarc.fr/ factsheets /populations/factsheet.asp?uno $=900$. Retrieved 201102-26. (cancer statistics often exclude non-melanoma skin cancers such as basal cell carcinoma which though very common are rarely fatal).

2. World Cancer Report. International Agency for Research on Cancer. 2008. http://www.iarc.fr/en/ publications/pdfs-online/wcr/2008/wcr_2008.pdf. Retrieved 2011-02-26.

3. Key TJ, Verkasalo PK, Banks E. Male Breast Cancer Treatment. National Cancer Institute. 2011. http:// www.cancer. gov/cancertopics/pdq/ treatment/ male breast/HealthProfessional. Retrieved 2011-02-26.

4. B Fisher. Laboratory and clinical research in breast cancer - a personal adventure: the David A. Karnofsky memorial lecture. Cancer Research, 1980;40(11):3863-74.

5. D McCready, C Holloway, W Shelley et al. Surgical management of early stage invasive breast cancer: a practice guideline. The Canadian Journal of Surgery 2005; 48(3):185-94.

6. VV Valero, AU Buzdar, and GN Hortobagyi. Locally advanced breast cancer. Oncologist 1996;1(1-2): 817.

7. A Makris, TJ Powles, SE Ashley et al. A reduction in the requirements for mastectomy in a randomized trial of neoadjuvant chemoendocrine therapy in primary breast cancer.Annals of Oncology 1998;9(11):1179-84.

8. Early Breast Cancer Trialists' Collaborative Group. Effects of radiotherapy and surgery in early breast cancer: an overview of the randomised trials. $N$ Engl $J$ Med 1995;333:1444-55. [PubMed]

9. Al-Ghazal SK, Fallowfield L, Blamey RW. Comparison of psychological aspects and patient satisfaction following breast conserving surgery, simple mastectomy and breast reconstruction. Eur J Cancer 2000;36:1938-43. [PubMed]

10. A Baildam, H Bishop, G Boland, et al. Oncoplastic breast surgerya guide to good practice. The European Journal of Surgical Oncology 2007;33(suppl 1):S1-S23.

11. W Audretsch and CAndree. Is mastectomy still justified and if, in which patients? Onkologie 2006; 29(6):243-45.

12. N Patani and R Carpenter. Oncological and aesthetic considerations of conservational surgery for multifocal/ multicentric breast cancer. Breast Journal 2010;16(3): 222-32.

13. MC Missana, I Laurent, L Barreau, and C Balleyguier. Autologous fat transfer in reconstructive breast surgery: indications, technique and results. The European Journal of Surgical Oncology 33(6):685-90.

14. F de Lorenzi. Oncoplastic surgery: the evolution of breast cancer treatment. Breast Journal 2010;16,(suppl 1):S20-S21.

15. KC Shestak, RR Johnson, RJ Greco, and SL Williams. Partial mastectomy and breast reduction as a valuable treatment option for patients with macromastia and carcinoma of the breast. Surgery Gynecology and Obstetrics 1993;177(1):54-56. 
16. C Tausch, T Hintringer, F Kugler, C Schmidhammer, M Bauer, and M Aufschnaiter. Breast-conserving surgery with resection of the nipple-areola complex for subareolar breast carcinoma. The British Journal of Surgery 2005;92(11):1368-71.

17. E Wagner, P Schrenk, GM Huemer, A Sir, M Schreiner, and W Wayand. Central quadrantectomy with resection of the nipple-areola complex compared with mastectomy in patients with retroareolar breast cancer. Breast Journal 2007;13(6):557-63.

18. V Galimberti, S Zurrida, V Zanini et al. Central small size breast cancer: how to overcome the problem of nipple and areola involvement. The European Journal of Cancer 1993;29(8):1093-96.

19. L Benelli. A new periareolar mammaplasty: the "round block" technique. Aesthetic Plastic Surgery 1990;14(2):93-100.

20. R Masetti, A Di Leone, G Franceschini et al. Oncoplastic techniques in the conservative surgical treatment of breast cancer: an overview. Breast Journal 2006;12(5), supple 2: S174-S180.

21. BO Anderson, R Masetti, and MJ Silverstein. Oncoplastic approaches to partial mastectomy: an overview of volume-displacement techniques. The Lancet Oncology 2005;6(3):145-47.

22. C Lassus. Reduction mammaplasty with short inframammary scars. Plastic and Reconstructive Surgery, 1986; 77(4):680-81.

23. C Lassus. Breast reduction: evolution of a techniquea single vertical scar. Aesthetic Plastic Surgery 1987;11(2): 107-12.

24. RM Rainsbury. Breast-sparing reconstruction with latissimus dorsi miniflaps. The European Journal of Surgical Oncology, 2002;28(8):891-95.

25. A Yelland and D Rainsbury. The use of the latissimus dorsi musculocutaneous flap for immediate correction of the deformity resulting from breast conservation surgery. The British Journal of Plastic Surgery 1999;52(5): 420-21.

26. JM Dixon, B Venizelos, and P Chan. Latissimus dorsi mini-flap: a technique for extending breast conservation. Breast 2002;11(1):58-65.

27. JE Rusby, N Paramanathan, SA Laws, and RM Rainsbury. Immediate latissimus dorsi miniflap volume replacement for partial mastectomy: use of intraoperative frozen sections to confirm negative margins. The American Journal of Surgery 2008;196(4): 512-18.

28. AM Munhoz, E Montag, E Arruda et al. Immediate conservative breast surgery reconstruction with perforator flaps: new challenges in the era of partial mastectomy reconstruction? Breast 2011;20(3):233-40.
29. N Patani and R Carpenter. Oncological and aesthetic considerations of conservational surgery for multifocal/ multicentric breast cancer. Breast Journal 2010;16(3):222-32.

30. H Zaha and S Inamine. Laparoscopically harvested omental flap: results for 96 patients. Surgical Endoscopy 2010;24(1):103-7.

31. JL Oh, MJ Dryden, WA Woodward et al. Locoregional control of clinically diagnosed multifocal or multicentric breast cancer after neoadjuvant chemotherapy and locoregional therapy. Journal of Clinical Oncology 2006; 24 (31):4971-75.

32. B Fisher, S Anderson, J Bryant et al. Twenty-year followup of a randomized trial comparing total mastectomy, lumpectomy, and lumpectomy plus irradiation for the treatment of invasive breast cancer. The New England Journal of Medicine 2002;347(16):1233-41.

33. A Resch, C Fellner, U Mock et al. Locally recurrent breast cancer: pulse dose rate brachytherapy for repeat irradiation following lumpectomy - a second chance to preserve the breast. Radiology 2002;225(3):713-18.

34. MC Smitt, K Nowels, RW Carlson, and SS Jeffrey. Predictors of reexcision findings and recurrence after breast conservation. International Journal of Radiation Oncology Biology Physics 2003;57(4):979-85.

35. H Liu, CK Huang, PC Yu et al. Retromammary approach for endoscopic resection of benign breast lesions. World Journal of Surgery 2009;33(12):2572-78.

36. EK Lee, SH Kook, YL Park, and WG Bae. Endoscopyassisted breast-conserving surgery for early breast cancer. World Journal of Surgery 2006;30(6):957-64.

37. K Yamashita and K Shimizu. Transaxillary retromammary route approach of video-assisted breast surgery enables the inner-side breast cancer to be resected for breast conserving surgery. The American Journal of Surgery 2008;196(4):578-81.

38. M Morrow. Minimally invasive surgery for breast cancer. The British Medical Journal 2009;338:57.

39. SE Singletary. Radiofrequency ablation of breast cancer. The American Surgeon 2003;69(1):37-40.

40. G Manenti, F Bolacchi, T Perretta et al. Small breast cancers: in vivo percutaneous US-guided radiofrequency ablation with dedicated cool-tip radiofrequency system. Radiology 2009;251(2):339-46.

41. S Nakamura, M Ishiyama, and H Tsunoda-Shimizu. Magnetic resonance mammography has limited ability to estimate pathological complete remission after primary chemotherapy or radiofrequency ablation therapy. Breast Cancer 2007;14(2):123-30.

42. S Oura, T Tamaki, I Hirai et al. Radiofrequency ablation therapy in patients with breast cancers two centimeters or less in size. Breast Cancer 2007;14(1):48-54. 